\title{
COMMERCIAL QUALITY REGULATION IN EUROPEAN COUNTRIES
}

\author{
Alexandra MOZSOLICS \\ HEO - Hungary \\ mozsolicsa@eh.gov.hu \\ Zsolt Birinyi \\ HEO - Hungary \\ birinyizs@eh.gov.hu
}

\author{
Zlatko ZMIJAREVIC \\ HERA - Croatia \\ zzmijarevic@hera.hr \\ Riccardo VAILATI \\ Italy (formerly with AEEG)
}

\author{
Math BOLLEN \\ LTU - Sweden \\ math.bollen@1tu.se \\ Werner FRIEDL \\ E-Control - Austria \\ werner.friedl@e-control.at
}

\begin{abstract}
The Council of European Energy Regulators has been publishing Benchmarking Reports on the Quality of Electricity Supply since 2001 on a regular basis. For the $5^{\text {th }}$ edition of the Benchmarking Report the 29 member countries of CEER were joined by the 9 NRA's from the Energy Community and the NRA from Switzerland. This paper contains the main results, findings and recommendations on commercial quality from this latest edition of the Benchmarking Report.
\end{abstract}

\section{INTRODUCTION}

The Council of European Energy Regulators (CEER) [1] periodically surveys and analyses the quality of electricity supply in its member countries (27 member states of the European Union, Iceland and Norway), addressing three major aspects: the availability of electricity (continuity of supply), its technical properties (voltage quality) and the speed and accuracy with which customer requests are handled (commercial quality).

These surveys and analyses take the form of CEER Benchmarking Reports on Quality of Electricity Supply. The first report was issued in 2001 [2], followed by the second, third and fourth editions in 2003, 2005 and 2008 respectively [3] [4] [5]. Similarly, information on the national regulations and its effects in the Energy Community Contracting Parties were gathered by the Energy Community Regulatory Board (ECRB) in the 2009 ECRB Report on the Quality of Electricity Service Standards and Incentives in Quality Regulation [6].

In addition to National Regulatory Authorities (NRAs) from CEER member countries, the 9 NRAs from the Energy Community Contracting Parties (hereafter EnC CPs) [7] and the National Regulatory Authority of Switzerland joined the benchmarking practice for the $5^{\text {th }}$ edition [8].

A detailed survey was sent out in March 2011 to the NRAs in CEER member countries and in the EnC CPs to obtain information on all three aspects of quality of supply. The survey contained detailed questions about existing and planned regulations on quality of supply, monitoring practices as well as questions on existing quality levels. In this paper we present the main results from the $5^{\text {th }}$ edition as well as the recommendations from CEER and ECRB on commercial quality. The main results on continuity of supply and voltage quality are presented in [9] and [10]. For more details the reader is referred to the full report [8].

\section{REQUIREMENTS, GROUPS OF STANDARDS}

Commercial quality is associated to transactions between electricity companies (either distribution system operators (DSO) or suppliers or universal suppliers or metering operators) and customers. Most of the services that can be requested by customers - e.g. new connection, elimination of voltage quality problems, answering a customer complaint, involve some commercial quality aspects, among which the timeliness of these services is the most frequent criterion.

In European countries four types of requirements are applied in the field of commercial quality (CQ):

- Guaranteed Standards (GSs) set minimum service quality levels which must be met in each individual case. If an electricity company fails to provide the level of service required by the GS, it must compensate the customer affected. The definition of GSs includes the following features:

- performance covered by the standard (e.g. estimation of the costs for the connection);

- required performance level - commonly determined in terms of response (fulfilment) time (e.g. 5 working days);

- economic compensation to be paid to the customer in case of non-performance.

- Overall Standards (OSs) refer to a given set of cases (e.g. all customer requests in a given region for a given transaction) and must be met with respect to the whole population in that set. OSs are defined as follows:

- performance covered (e.g. connection of a new customer to the network);

- minimum performance level (commonly in \% of cases), which has to be met in a certain time limit (e.g. $90 \%$ of new customers have to be connected to the distribution network within 20 working days).

- Other Available Requirements (OARs). In addition to GSs and OSs, regulators (and/or other competent parties) can issue requirements in order to achieve a 
certain level of commercial quality. These quality levels can be set as the regulator deems appropriate, e.g. a minimum level which must be met for all customers at all times. If the requirements set by the regulators are not met, the regulator can impose sanctions (e.g. financial penalties).

- Only Monitoring (OMs). Before issuing GSs and OSs, regulators (and/or other competent parties) can monitor performances of electricity companies, in order to understand the actual quality level and to publish - when deemed appropriate - the actual data on services provided to the customers.

In the latest edition of the Benchmarking Report 15 commercial quality indicators, divided in four groups, were selected for survey using the list of most frequently applied standards from past Benchmarking Reports as a basis. The four groups are:

- Connection;

- Customer care;

- Technical Service and

- Metering and Billing.

For the first time in the history of Benchmarking Reports, historical data on commercial quality for a 3-year period (2008-2010.) was surveyed.

\section{MAIN RESULTS OF THE BENCHMARKING}

The analysis of the reported data clearly shows that in CEER member countries with advanced commercial quality regulation the use of overall standards has been decreasing while more guaranteed standards have come into force over time. This process is likely to continue in other countries in the near future as well. However, in many countries other requirements applicable to each single transaction are applied as well, albeit without compensation to the customer in case of non-compliance or without any sanction to the electricity company. This last practice is rather widespread among the EnC CPs since CQ regulation and customer protection is in early development. Such OAR standards are easily evolved into GS standards, additionally supporting the trend for increasing the adoption of GSs across Europe. From the customer protection point of view, the most appreciated regulation is based on concrete compensation which translates to guaranteed standards with automatic compensation or, to a lesser extent, towards OS or OAR with the option of sanctioning.

\section{Connection}

The survey revealed that commercial quality standards associated with connection to the network are of primary importance in the responding countries. This is mainly due to the fact that information about the network access conditions and speed of connection are of high priority to customers. As connection is mainly related to distribution, the related standards are only applicable to DSOs. Standards for connection-related activities often have a complex structure, depending upon the complexity of the work to be done. The requirements for indicators of the group "Connection" have been defined according to different criteria in the responding countries, e.g. voltage level, connection capacity or the complexity of the project. An example of the diversity of regulation in case of one of the connection-related standards is shown in Table I.

TABLE I

EXAMPLES OF CRITERIA BY WHICH THE STANDARD "TIME FOR COST ESTIMATION FOR SIMPLE WORKS" CAN BE DISTINGUISHED

\begin{tabular}{|c|c|c|}
\hline Country & Criteria & Obligation \\
\hline \multirow{3}{*}{$\begin{array}{l}\text { Great } \\
\text { Britain }\end{array}$} & $\begin{array}{l}\text { single LV service demand } \\
\text { connection }\end{array}$ & 5 working days \\
\hline & $\begin{array}{l}\text { a small project demand } \\
\text { connection }\end{array}$ & 15 working days \\
\hline & in other cases & 25 days \\
\hline \multirow{3}{*}{ Ireland } & no visit to site is required & 7 working days \\
\hline & a visit to site is required & 15 working days \\
\hline & $\begin{array}{l}\text { larger developments or }>100 \\
\mathrm{~kW} \text { or in MV }\end{array}$ & 90 working days \\
\hline \multirow{2}{*}{ Italy } & $\begin{array}{l}\text { automatic compensation } \\
\text { doubles }\end{array}$ & after 40 working days \\
\hline & $\begin{array}{l}\text { automatic compensation } \\
\text { triples }\end{array}$ & after 60 working days \\
\hline \multirow{5}{*}{ Portugal } & supplies <15 kW (LV) & 5 days \\
\hline & $\begin{array}{l}\text { other without substation } \\
\text { investment (LV) }\end{array}$ & 10 days \\
\hline & $\begin{array}{l}\text { other supplies with substation } \\
\text { investment (LV) }\end{array}$ & 20-30 days \\
\hline & $1-66 \mathrm{kV}$ & 40 days \\
\hline & $>66 \mathrm{kV}$ & 60 days \\
\hline
\end{tabular}

Most countries have made significant improvement in the performance of connection-related standards in the past years. Hungary is a good example, where the overall performance indicator shows a prominent improvement of $6 \%$ during 2008-2010. The average performance of the standard "Time for connecting new customers to the network" is below 5 days in most CEER countries, but the actual performances varies a lot across Europe. This mainly arises from the different interpretation of the same standard by the responding countries, e.g. in France only new buildings connected for the first time to the network are covered by the above standard, which is the reason for the quite high average performance time, while the excellent performance of Italy is due to the facts that only the new connections which do not require interventions outside the meter are included in the standard and that smart meters are rolled out in whole country. Therefore, standards need to be based on accurate and harmonised definitions. This is significant for EnC CPs where connection-related standards and technical service standards and statistics are diverse, although procedures and regulatory frameworks are somewhat similar.

\section{Customer Care}

The standards in the group "Customer Care" are applicable mostly to DSOs but also to suppliers. The importance of punctuality of appointments with customers is demonstrated by the fact, that most countries apply GSs with 
compensations when the requirements of the standard are not met. The survey shows that the most developed area of customer care relates to contacts in writing. However in some countries other forms of contacts are also regulated, e.g. requirements are set on call centres' service level in Estonia, Italy, Hungary and Portugal, and in the latter two countries the average waiting time at customer centres is also regulated.

The performance of customer care related indicators was quite high in 2008-2010 in most of the responding countries. The data on the average performance time of response to customer complaint and enquiries in 2008-2010 clearly show that customers receive a response to their notice within an average of 15 days. In Portugal not only the written but also all the phone enquiries are considered, which explains the extremely short $(<1$ day) average response times.

It should be emphasized that all customer related standards require systems that track a specific customer with a specific issue. This calls for customer relationship management or similar systems, as well as direct monitoring of interaction with customers. Among EnC CPs, DSOs and incumbent companies are not yet focused on customers and do not use such systems which explains why this group of standards is the least developed aspect of their CQ regulation.

\section{Technical Service}

The indicators of the group "Technical Service" relate to distribution activities, therefore these standards exclusively refer to DSOs. The exact time needed to rectify the problem (e.g. voltage disturbance) or to implement temporary solutions in case of a customer complaint varies a lot and depends on the complexity of the given situation. Only three countries reported existing numerical GSs for the standard "Time between the date of the answer to the VQ complaint and the elimination of the problem", and only one (Hungary) requires automatic compensation to be paid to customers in case the requirements are not fulfilled. Italy entered this group of countries since new 2012 regulation. One of the most commonly applied indicators in the group "Technical Service" - "Time until the start of the restoration of supply following failure of a fuse of DSO" - in some countries depends on the customer's geographic location, the voltage level, the time of the call (day or night) and on whether the customer possesses any electronic medical device needed for survival (Table II.).

The widespread application of the standard "Time for giving information in advance of a planned interruption" (14 CEER countries) indicates the importance of minimizing the negative consequences of the interruptions by giving customers the chance to take proper measures. The deadline for the notification varies significantly (from 24 hours to 15 days) among countries. Three countries apply compensation in case of non-fulfilment. In some countries standards or regulatory frameworks differentiate customer groups in respect to the timeliness and communications methods (e.g. in Croatia commercial customers must be informed $48 \mathrm{~h}$ in advance and households $24 \mathrm{~h}$; in Ukraine, legal entities have a repeated notice 1 day ahead).

TABLE II

EXAMPLES OF CRITERIA BY WHICH THE STANDARD "TIME UNTIL THE START OF THE RESTORATION OF SUPPLY FOLLOWING FAILURE OF FUSE OF DSO" AND COMPENSATION CAN BE DISTINGUISHED

\begin{tabular}{|c|c|c|}
\hline Country & Criteria & Obligation \\
\hline \multirow{2}{*}{$\begin{array}{c}\text { Czech } \\
\text { Republic }\end{array}$} & in Prague & 4 hours \\
\hline & elsewhere & 6 hours \\
\hline \multirow{5}{*}{ Hungary } & $\begin{array}{l}\text { more than } 50,000 \text { inhabitants, on week } \\
\text { days }\end{array}$ & 4 hours \\
\hline & $\begin{array}{l}\text { more than } 50,000 \text { inhabitants, on } \\
\text { weekends and between } 5,000 \text { and } 50,000 \\
\text { inhabitants, on working days }\end{array}$ & 6 hours \\
\hline & $\begin{array}{l}\text { between } 5,000 \text { and } 50,000 \text { inhabitants, at } \\
\text { weekends and less than } 5,000 \text {, on working } \\
\text { days }\end{array}$ & 8 hours \\
\hline & $\begin{array}{l}\text { less than } 5,000 \text { inhabitants, at weekends } \\
\text { and on periphery of municipalities }\end{array}$ & 12 hours \\
\hline & on periphery of municipalities & 12 hours \\
\hline \multirow{2}{*}{ Italy } & $\begin{array}{l}\text { automatic compensation doubles after } \\
\text { double standard time }\end{array}$ & \\
\hline & $\begin{array}{l}\text { automatic compensation triples after triple } \\
\text { standard time }\end{array}$ & \\
\hline \multirow{3}{*}{ Portugal } & $\begin{array}{l}\text { for customers dependent on medical } \\
\text { equipment }\end{array}$ & 3 hours \\
\hline & in areas classified as "C" (rural areas) & 5 hours \\
\hline & in other cases & 4 hours \\
\hline
\end{tabular}

The standard "Time until the restoration of supply in case of unplanned interruptions" which is used in 13/5 CEER countries/EnC CPs - depends on the voltage level and the location of the interruption.

The technical service-related indicators remained either about the same or improved slightly in every reporting country over the period of 2008-2010.

\section{Metering and Billing}

The commercial quality standards of the group "Metering and Billing" refer mainly to DSOs, in some countries to Metering Operators, while suppliers are regulated only in Hungary and monitored in Estonia. Standards for the time from notice to pay until disconnection typically varies between one and two weeks. Some countries, apply countryspecific considerations for this issue, for example Finland and Hungary.

"Time for restoration of power supply following disconnection due to non-payment" is one of the most widely used indicators with an overly small expected value, which indicates the effort of the NRAs to incentivise the DSOs to perform the reconnection of customers as soon as possible after the debts and the fee of the disconnection are paid by the customer. In half of the reporting CEER countries reconnection must be completed by the DSO within one (working) day. For the EnC CPs, the median value is two days.

The commercial quality indicators of the group "Metering and Billing" are the least monitored in CEER countries compared to the standards of the other three groups. 
Historical data (which was reported by only three countries) shows slight improvements in the performance.

\section{COMPENSATIONS TO CUSTOMERS}

Different payment methods and ways of execution of payment are applied for the customers in the CEER countries if Guaranteed Standards are not fulfilled. The amount of compensation varies between the countries and depends on the customer sector, on the voltage level and on the time of the performance. In Italy, for example, the automatic compensation doubles and triples when the actual time of the performance is more than two times or three times the time limit set by the standard, respectively. In four countries the affected customers get automatic compensation in case the requirements are not met, while in other countries compensation is paid upon request of the customer.

\section{CONCLUSIONS}

A number of findings and recommendations were obtained from the survey results and its analysis. Strongly summarized formulations of those findings and recommendations are listed below. For specific details and exact formulations, the reader is referred to the text of the Benchmarking Report [8].

$\checkmark$ Finding \#1: There is a widespread use of commercial quality standards in European countries. This demonstrates that great attention is paid by the European NRAs to the quality of services provided to customers.

$\checkmark$ Recommendation \#1: Periodically review the national regulations of commercial quality standards, taking into account the development of national conditions and the expectations of the customers.

$\checkmark$ Finding \#2: There is a trend for increasing the adoption of guaranteed standards (GSs).

$\checkmark$ Recommendation \#2: Enforce GSs in order to protect customers better. Apply GSs tied to automatic compensation or other regulatory requirements (overall standards or other available requirements) associated with the option of imposing sanctions in case of noncompliance with such requirements.

$\checkmark$ Finding \#3: Most commercial quality frameworks prioritize on actual electricity supply (access to electricity).

$\checkmark$ Recommendation \#3: Properly prioritise the national regulations of commercial quality. Assess customer priorities before creating new regulatory framework accordingly.

$\checkmark$ Finding \#4: There are proven opportunities of high tech developments for improving quality for customers.

$\checkmark$ Recommendation \#4: Maximise the benefits of high tech developments for customers.

$\checkmark$ Finding \#5: There are new trends in regulating customer relations.

$\checkmark$ Recommendation \#5: Develop the regulation of customer relations. Monitor the performance of the distribution system operators and universal suppliers in the field of customer contacts by phone and of personal visits at customer centres in order to get information for a future regulation.

All finding and recommendations produced by CEER NRAs are relevant to Energy Community Contracting Partners but with somewhat different significance and urgency. This may be perceived through findings and recommendations of ECRB presented in the Annex to [8].

The Benchmarking Reports play an important role in the exchange of information among European countries on quality indicators, actual quality levels, regulatory mechanisms and best practises for regulating the quality of supply.

\section{ACKNOWLEDGEMENT}

The contributions are acknowledged from many others to the material that formed the basis for this paper, especially the other members of the Electricity Quality of Supply and Smart Grids Task Force within CEER and the ECRB Customer Working Group within the Energy Community. The text of this paper is based on the text in the $5^{\text {th }}$ Benchmarking Report on Quality of Electricity Supply. Where the text of this paper deviates from the text of the $\mathrm{BR}$, it is the personal opinion of the authors and not necessarily the opinion of CEER or ECRB, neither of the national regulatory authorities the authors work for.

\section{REFERENCES}

[1] Council of European Energy Regulators, http://www.energy-regulators.eu

[2] Quality of Electricity Supply: Initial Benchmarking on Actual Levels, Standards and Regulatory Strategies", CEER, April 2001.

[3] Second Benchmarking Report on Quality of Electricity Supply, CEER, September 2003.

[4] Third Benchmarking Report on Quality of Electricity Supply 2005, CEER, December 2005.

[5] $4^{\text {th }}$ Benchmarking Report on Quality of Electricity Supply, CEER, December 2008.

[6] ECRB Report on the Quality of Electricity Service Standards and Incentives in Quality Regulation, ECRB, July 2009.

[7] Energy Community, http://www.energycommunity.org

[8] $5^{\text {th }}$ Benchmarking Report on Quality of Electricity Supply, CEER and ECRB, December 2011.

[9] W. Friedl et al., A European benchmarking of continuity of supply regulation. This conference.

[10] M. Bollen, et al., A European benchmarking on voltage quality regulation. This conference. 